\title{
Comfort aspects important for the performance and safety of kitesurfing
}

\author{
Lina Lundgren, ${ }^{\mathrm{a},}$, Sofia Brorsson ${ }^{\mathrm{a}}$ and Anna-Lisa Osvalder ${ }^{\mathrm{a}, \mathrm{b}}$ \\ ${ }^{\mathrm{a}}$ Biological and Environmental Systems, Halmstad University, Box 823, 30118 Halmstad, Sweden \\ ${ }^{\mathrm{b}}$ Division of Design and Human Factors, Chalmers University of Technology, 41296 Gothenburg, Sweden \\ Corresponding author: lina.lundgren@hh.se
}

\begin{abstract}
Equipment used in sports is of great importance, especially when the equipment is in direct contact with the athlete or is important for safety. In the sport kitesurfing environmental factors and the equipment design are crucial for the comfort and safety. The participants' choice and opinion of equipment can show which factors are considered most important for the performance and to reduce risk for injury. This study has evaluated self-reported information from the participants about what equipment they use, comfort of the equipment and if the equipment has contributed to any injuries. The methods used were questionnaires $(\mathrm{n}=206)$ and interviews $(\mathrm{n}=17)$, which in combination allows to assess the problem both quantitatively and qualitatively. The results showed that supported leading edge kites are most frequently used, with a waist harness and foot straps to attach the feet. The choice of kite type was mainly based on the discipline of riding for the respondent. Some issues concerning comfort of riding and injury risk the respondents did relate to the design of harness and foot straps. The information from this study can be used for development strategies for industry manufacturers and for further studies in the area of equipment design and biomechanics.
\end{abstract}

Keywords: sport equipment, kitesurfing, injury risk, product comfort

\section{Introduction}

Equipment used in sport is of great importance, especially when the equipment is in direct contact with the athlete or has impact on safety. In the sport kitesurfing, equipment and environmental factors have been shown to have large impact on safety of the sport $[6,8,9,12]$. Also for ergonomic issues, the equipment has to be well designed for the athlete to enable maximum performance and to reduce injury risk $[1,10]$. The sport kitesurfing is still young (evolved in the late 1990's), and the equipment has developed in a short time. Today, there are numerous types of kites, harnesses and boards to choose from. Earlier studies have shown the types of injuries that are associated to the sport and factors that are important for safety $[8,9,12]$. For example, this research has shown that the use of a quick-release safety system, that enables the participant to detach the equipment from oneself, have become important to prevent accidents and is now available on all kites [12]. However, little is reported about which equipment that is used and how it affects the comfort and performance for the participants.

Comfort is a subjective measure of the perception of a situation, indicating well-being and relaxation [14], and is influenced by other factors, representing an interaction of the task itself, environmental factors, and human factors. Hence, the product will be a substantial part of the situation and will influence the comfort sensation both physically and aesthetically [2]. Furthermore, a feeling of discomfort would indicate a need for change in the interaction of these factors [13]. When discussing the comfort concept in this study, we relate to the athlete's perception of how their equipment influence performance and injury risk when performing kitesurfing.

The aims of this study were to evaluate selfreported information about i) which equipment the participants of kitesurfing use (kites, harnesses, feet

\footnotetext{
${ }^{*}$ Corresponding author. E-mail: lina.lundgren@hh.se.
} 
attachments) ii) how the equipment affect their performance and comfort, and iii) if the equipment contributes to any injuries.

\section{Method}

In this study, 223 persons with experience of kitesurfing were included to evaluate kitesurfing equipment. The data was collected through an international web questionnaire $(n=206,189$ males and 17 females) and interviews ( $\mathrm{n}=17,16$ males and 1 female). Their age ranged from 16-62 with a mean of 30.8 and 30.1 respectively. The questionnaire consisted of 50 questions and took about 20 minutes to perform. It was available for one month and linked to from different kitesurfing forums and web pages. The purpose of the questionnaire was to address information about the equipment and equipment-related injuries. The interviews were conducted individual by selfconfrontation and contained 15 semi-structured questions about the equipment they used and why, how the equipment affects comfort and perceived injury risk. The interviewees were asked for participation at kitesurfing events and forums. The use of questionnaires and interviews supplemented the quantitative, international data with qualitative information from Swedish participants [11]. For data analysis of the questionnaires frequencies were analyzed and Pearson's chi square test was used for statistical comparisons between groups. The qualitative data was analyzed by categorising quotations from the interviews into a chart of systematically labelled answers [3].

\section{Results}

\subsection{Choice of kites}

There were four different types of kites used among the respondents. Although many respondents mixed between these types $(n=55)$, most of them used kites with a supported leading edge (SLE) $(n=112)$ (Fig. 1a). C-kites, were used by 90 respondents (Fig. 1b) and 60 used kites that are a mix of these two - hybrids. Foil kites were used by 16 persons in the survey. The C-kite was mainly chosen by participants performing a discipline of kitesurfing called 'wake style', which is associated with powerful acrobatic air movements. The experience of using C-kites compared to SLE kites was explained by the interviewees as most obvious when riding unhooked from the harness (i.e. attached to the kite through the arms instead of the harness). In the unhooked situation the C-kite was perceived as easier to keep control of, whereas the respondents explained the SLE kite to increase its tension more, making it harder to control. While riding hooked into the harness the respondents claimed it to be more relaxed to ride an SLE kite, because the wider sheeting range allows the SLE kite not to increase as much power, in case of a sudden change of wind speed.

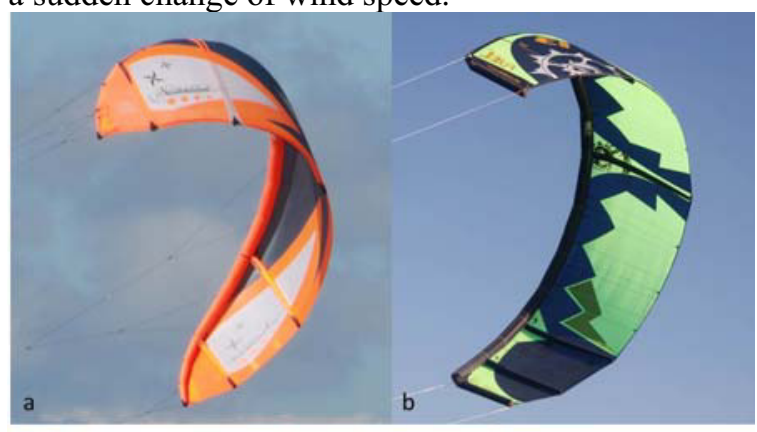

Figure 1

SLE-kite (a) was the most used type of kite and C-kite (b), the second most

\subsection{Harness aspects}

Regarding harnesses, $85 \%$ of the questionnaire respondents used waist harness and these participants were able to perform advanced tricks to a wider extent than those who used sit harness $(\chi(1)=10.8$, $\mathrm{p}<0.01)$. It was also more common with perceived musculoskeletal stress in lower back and abdominal muscles if using waist harness $(\chi(1)=9.5, p<0.01)$. The interviewees agreed that the most important characteristics for a harness were that it stayed in place around the lumbar part of the back and did not slide upwards during kitesurfing (Table 1). Another important notion was that the harness should give adequate support to the back and spread out the pressure without chafing. One respondent stated; "It should not be too hard in the back, but it could follow the lumbar part of the back and give support to the back."

Another aspect that was brought up was that the cushioned plate located anterior on the harness was important to protect the ribs from being injured by the spreader bar if a sudden pull or hard fall occurred. All of the interviewees had previous experiences with harnesses that were not fitting properly to their body, but most of them $(n=13)$ had found one that they were satisfied with. 
Table 1

Important characteristics of harnesses, as stated by $\mathrm{N}$ of the interviewed respondents

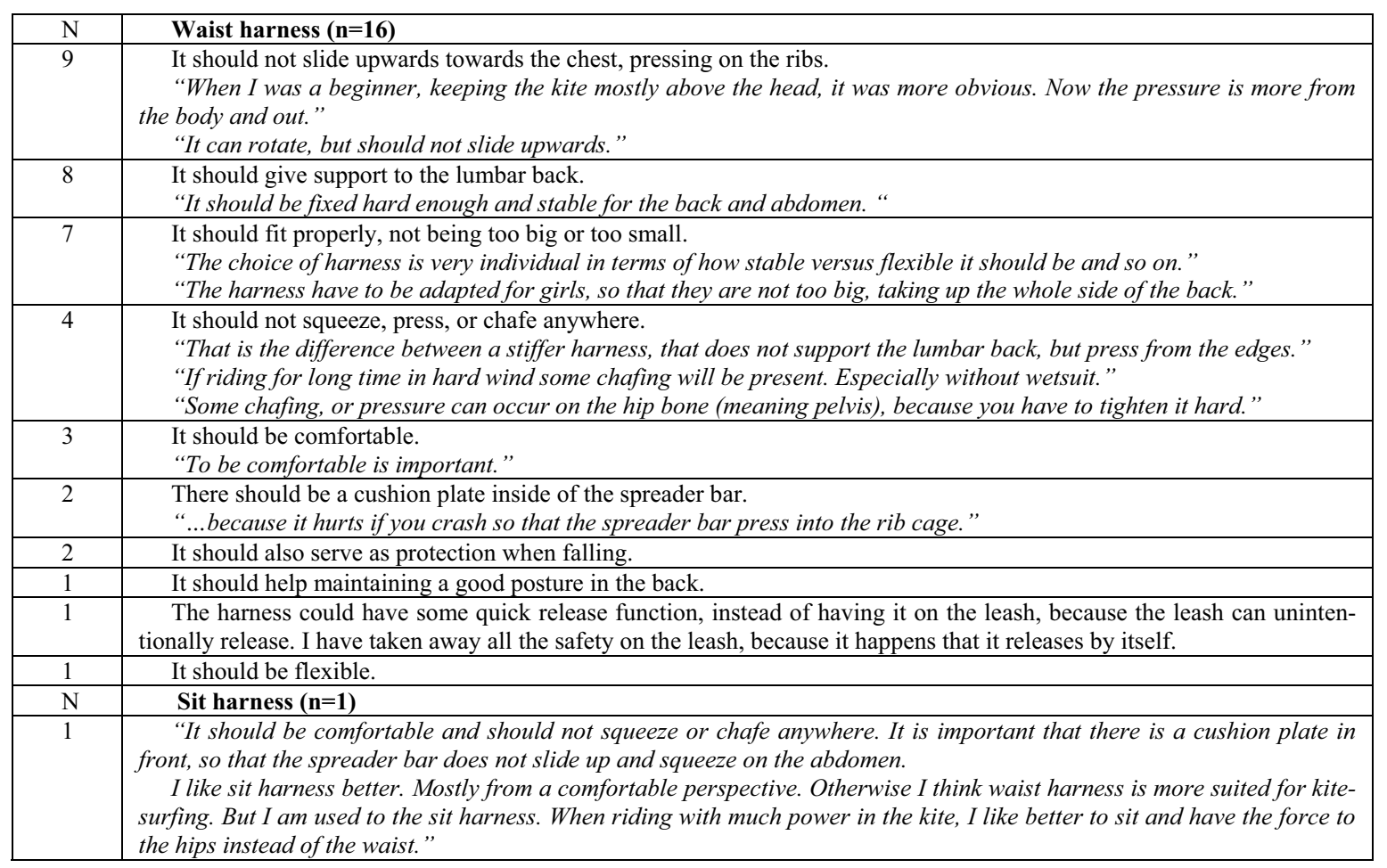

\subsection{Foot straps}

To attach the feet to the board, straps or bindings are used (Fig. 2). Straps were used by most respondents $(92 \%)$ for attaching the feet to the board and sometimes combined with a strap around the heel to keep the board attached to the feet when jumping (10\% of respondents reported this). A female interviewee mentioned that it was hard for her to find suitable straps for her small feet, hence she used heel straps not to fall out of the straps while jumping. Others (12\%) sometimes or always used bindings instead of straps to keep the board attached to the feet and to achieve a feeling similar to wakeboarding when kitesurfing. They explained that it is good to know that the board will stay attached to the feet during tricks, but on the other hand that an unfinished rotation can cause a very sudden stop, hence a hard fall. The users of bindings also explained them to require a different technique compared to riding a board with straps. A few $(n=5)$ reported that they mainly perform waveriding without any straps on the board.

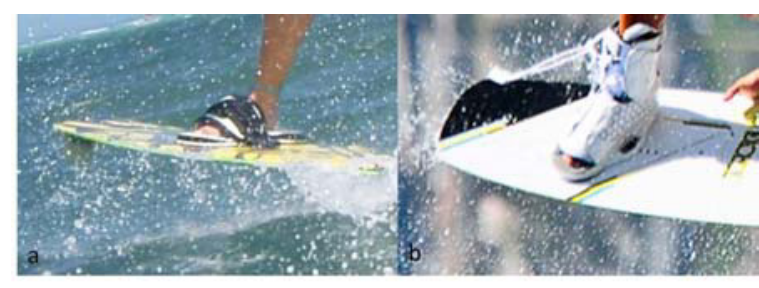

Figure 2

Straps (a) and bindings (b) used to attach the feet to the board.

\subsection{Equipment and injuries}

Of 251 self-reported injuries (included wounds and lacerations) it was reported in 76 cases that the equipment contributed to the extent of the injury, e.g. one foot slipping out of the strap, a hard impulse while landing, bruises or cutting from a fin, the kite continued to pull after fall or the harness pressed against thorax. From the interviews there were 9 cases where the equipment was explained as contributing to the extent of their injury; whereof 5 were bruises and wounds from hitting the board. One injury was due to the participant not being able to get the board off the feet, because the use of heel straps. 
In two cases the injuries were due to one foot slipping out of the strap before landing a jump, just as was reported by 9 of the questionnaire respondents who sustained an injury. Due to the low number of participants using bindings, we could not distinguish the use of bindings or straps in relation to perceived pain or injuries in knee or ankle while kitesurfing.

\section{Discussion}

This study assessed participants' experiences of kitesurfing equipment and showed that ergonomic variables such as comfort and proper fit are important for the safety of the sport. Most respondents use some kind of SLE kite, waist harness and straps on a twintip board. The participants choose equipment specific for their type of riding, being thorough that it should fit properly. Most equipment is available in different sizes and offers possibilities to adjust the size for individual adaptation. However, some kitesurfers experience ergonomic problems such as rashes, improper size or lack of support associated to some products. How well kitesurfing equipment fits different body sizes and anthropometric measures is not scientifically evaluated yet, but is clearly an interesting subject for future research. For example, there seem to be some problems with the straps that attach the board to the feet, because several injuries to the lower extremities occurred in combination with one foot slipping out of the strap. This issue indicates a need for development of the feet attachment, in order to find solutions that allow to get rid of the board, but not accidentally loose one foot attachment. The results show that injury can occur both when using extra straps around the heels and no heel straps, although the heel straps are meant to keep the board on the feet, just as bindings.

Furthermore, several respondents claimed that the impulse from the board when landing from jumps, or riding on a wavy surface, can cause discomfort, or even contribute to injury. Although the foot pads and boards are of differing material properties between products, there could be a need to investigate this issue further in order to find a suitable stiffness of the foot pad for the amount of reaction force that the athlete is exposed to.

The position of the harness was explained important by the participants and a harness higher up on the thorax could result in effects on the performance. With a harness higher up on thorax, the steering bar position would differ in position in relation to the arms and the moment arm from the harness hook to the board and lower extremity muscles would increase. For comfortable use, it is important that the harness design gives adequate support to the back when carrying the load from the kite, spreading the tension force on a large surface of the back. However, how well kitesurfing equipment does fit different body sizes and anthropometric measures is not scientifically evaluated, to the authors' knowledge. Further studies examining these aspects of kitesurfing equipment are advised according to the results of this study. Other studies have proposed further research regarding equipment design and biomechanics suitable for sports where equipment is crucial for performance and safety $[1,10]$. There are some harnesses specially designed for females, but because of the few female respondents in this study, no gender related results are possible to display.

Respondents expressing comfort, and safety issues associated to the system of the kite (steering bar, lines, kite), were mainly referring to sudden pulls from the kite or loss of control for a moment. However, there are several safety aspects built into the kite system, such as ability to depower through changing the angle of attack of the kite, quick-release system, line system management etc. Very few respondents commented on these systems, although they do require some cognitive understanding, coordination and reaching ability to be used properly [4]. The bar is the only equipment to which the upper extremities are in direct contact during kitesurfing and we have reported in earlier studies that problems such as perceived musculoskeletal stress and pain occur in this area among participants of kitesurfing [5]. The reason for this is unclear, but problems reported as 'tennis elbow' could be a result of the kite and bar characteristics, if the equipment require much force to be steered or have high bar pressure when sheeting. Also, the shape and design of the bar can influence the capacity of forearm muscles to work during execution of the sport, because of the pronated grip that is required.

Comfort aspects that have effect on performance or injury risk should be considered for development of the equipment, in order to allow the participant to use biomechanically advantageous body postures and loading situations. However, comfort is hard to quantify and might not be generalizable at all populations [7]. Practically this means that the products ideally should be aimed at a specific population and be evaluated according to ergonomic principles of posture and force application throughout the development process. 


\section{Conclusion}

The results showed that there was an individual preference of which kitesurfing equipment to use, depending on the discipline and type of riding, but that most participants use SLE-kites with a waist harness and straps on a twin tip board. The participants agree on the importance of the equipment for comfort and safety issues, being thorough that it should fit properly. Among the reported problems

\section{References}

[1] Cottam M, Hodskinson MG, Sherrington I (2002) Development of a design strategy for an established semi-technical product. A case study of a safety harness for tree workers. Design Studies 23 (2002), 41-65.

[2] De Looze M, Kuijt-Evers L, Van DIE, Euml, N J Sitting comfort and discomfort and the relationships with objective measures. Ergonomics 46 (2003) , 985997.

[3] Hauw D, Renault G, Durand M, How do aerial freestyler skiers land on their feet? A situated analysis of athletes' activity related to new forms of acrobatic performance. Journal of Science and Medicine in Sport 11 (2008), 481-486.

[4] Lundgren L, Bligård L-O, Brorsson S, Osvalder A-L, Implementation of usability analysis to detect problems in the management of kitesurfing equipment. Procedia Engineering 13 (2011), 525-530.

[5] Lundgren L, Brorsson S, Hilliges M, Osvalder A-L, Sport performance and perceived musculoskeletal stress, pain and discomfort in kitesurfing. International Journal of Performance Analysis in Sport 11 (2011), 142-158.

[6] Lundgren L, Brorsson S, Osvalder A-L, Injuries related to kitesurfing. World Academy of Engineering and Technology 77 (2011).

[7] Mündermann A, Nigg BM, Stefanyshyn DJ, Humble RN Development of a reliable method to assess with the equipment were issues such as improper fit of the equipment and lack of support, which could have effect on comfort, performance, or contribute to injury risk if the equipment cannot be controlled, or changes its position. The equipment was reported to contribute to injuries in cases when one foot slipped out of the strap on the board, or the harness produced high pressure or rashes on the thorax segment. footwear comfort during running. Gait \& Posture 16 (2002), 38-45.

[8] Nickel C, Zernial O, Musahl V, Hansen U, Zantop T, Petersen W, A Prospective Study of Kitesurfing Injuries. The American Journal of Sports Medicine 32 (2004), 921-927.

[9] Petersen W, Nickel, C., Zantop, T., Zernial, O., Verletzungen beim Kitesurfen. Der Orthopäde 34 (2005), 419-425.

[10] Reilly T, Lees A, Exercise and sports equipment: Some ergonomics aspects. Applied ergonomics 15 (1984), 259-279.

[11] Sandelowski M, Combining qualitative and quantitative sampling, data collection, and analysis techniques in mixed-method studies. Research in nursing \& health 23 (2000) , 246-55.

[12] Spanjersberg WR, Schipper IB, Kitesurfing: when fun turns to trauma-the dangers of a new extreme sport. The Journal of Trauma 63 (2007), 76-80.

[13] Vink P, Hallbeck S, Editorial: Comfort and discomfort studies demonstrate the need for a new model. Applied ergonomics In Press (2011), Corrected Proof.

[14] Zhang L, Helander MG, Drury CG Identifying Factors of Comfort and Discomfort in Sitting. Human Factors: The Journal of the Human Factors and Ergonomics Society 38, (1996), 377-389. 